\title{
Experience of Laparoscopic Gynecological Surgeries at Kathmandu Model Hospital
}

\author{
Bajracharya N, ${ }^{1}$ Dangal G, ${ }^{1}$ Karki A, ${ }^{1}$ Pradhan H, ${ }^{1}$ Shrestha R, ${ }^{1}$ Bhattachan K, ${ }^{1}$ Poudel R ${ }^{1}$ \\ Department of Obstetrics and Gynecology, Kathmandu Model Hospital, Nepal
}

Received: 23-May-2017; Accepted: 30-June-2017

\begin{abstract}
Aims: Laparoscopy has become the most common procedure in recent set-ups. It is now a major diagnostic as well as therapeutic modality for infertility, endometriosis, extrauterine pregnancy and benign ovarian tumors. The aim of the study was to share the experience of gynecological laparoscopic surgeries performed at Kathmandu Model Hospital.
\end{abstract}

Methods: A descriptive study was carried out at Kathmandu Model Hospital from $1^{\text {st }}$ January 2011 to $1^{\text {st }}$ May 2017. All the patients who underwent gynecological laparoscopic surgeries were analyzed for the indication, type of procedure and its complications.

Results: Out of 217 , majority $24.4 \%(\mathrm{n}=53)$ patients were in age group $26-30$ years. There were $51.1 \%(111)$ cases of ovarian cyst, $12.44 \%(27)$ cases of ectopic pregnancy. Eight cases were done with surgeons for cholecystectomy and ovarian cystectomy or hysterectomy. There were $15 \%(\mathrm{n}=32)$ cases of diagnostic laparoscopy. Total laparoscopic hysterectomy was done in $16 \%(n=33)$ cases. Conversion to laparotomy was done in $3 \%(8)$ cases. There was one case of vascular injury. Most common immediate post-operative complaint was variable degree of pain, managed with parenteral and oral analgesics. Oral diet started at 4-6th hour post-operatively, and mobilization started after 24 hours. 75\% (164) cases had a hospital stay of 2 days and $25 \%(53)$ cases stayed for 3 days.

Conclusions: Laparoscopic surgery at our hospital has been well demonstrated in terms of reducing postoperative pain and decreasing postoperative morbidity, short hospital stay, and less postoperative recovery time. However, adequate advanced training and devices are needed to perform skillful laparoscopic surgeries.

Keywords: cystectomy; gynaecological laparoscopic surgeries; hysterectomy.

DOI: http://dx.doi.org/10.3126/njog.v12i1.18988

\section{INTRODUCTION}

Laparoscopy is a revolution in gynecological surgery as it is safe and less invasive. It was first performed by Jacobeus in Sweden in $1910 .{ }^{1}$ History shows that in gynecological endoscopy surgery, there was massive enthusiasm in the beginning but its growth was not as expected. The major hurdle for this is the learning curve for endoscopy surgeries.In developing countries like Nepal, we are still in a crawling phase, the major reason for this being lack of expertise.First laparoscopic gynecological operation done in Nepal was tubal sterilization in 1971 in Maternity Hospital. Padhye $^{2}$ in her study of 1600 patients of laparoscopic sterilization under local anesthesia found the method to be simple, satisfactory and cheap.Initially, its use in gynecology was restricted to diagnostic purpose; gradually it expanded to therapeutic modalities in

\section{CORRESPONDENCE}

Dr Nishma Bajracharya

Department of Obstetrics and Gynecology, Kathmandu Model

Hospital, Nepal

Email: nishu_bajra@hotmail.com

Phone: +977-9860157654 different gynecological problems. We at Kathmandu Model Hospital have been performing laparoscopic surgeries since 2011 for indications including both diagnostic and therapeutic operations. This study aimed to share the experience of laparoscopic gynaecological operations done in Kathmandu Model Hospital.

\section{METHODS}

This study was carried out in Kathmandu Model Hospital from $1^{\text {st }}$ January 2011 to $1^{\text {st }}$ May 2017. All the patients subjected to gynecological laparoscopic procedures were taken for study. Ethical approval was obtained from ethical review board of phectNEPAL/ Kathmandu Model Hospital. The patients were explained about the type of procedure, duration of procedure, intra and post-operative complication, post operative stay and need of laparotomy. Informed consent was obtained from the patient for surgery.

A pre-operative assessment was done in all the patients that included clinical examination, blood investigations, abdomen-pelvis scan and determination of tumor markers whenever indicated. 
All elective cases were admitted on the day of surgery with bowel preparation pre operatively. General anesthesia with endotracheal intubation was done in all cases. During the procedure, the patient was placed in lithotomy trendelenburg position. Abdomen was opened with open technique using a Hasson Cannula. A one cm supra or infra-umbilical incision was given and pneumoperitoneum was created.Total laparoscopic hysterectomy (TLH) was done with standard technique with vault closure using either endosuture or vaginally. Ovarian cystectomy was performed by either enucleating the ovarian cyst, deroofing or aspirating it followed by removal of the cyst wall or oophorectomy where needed. Routine post-operative care was given and patients received parenteral antibiotics for first 24 hours followed by oral antibiotics for 5 days. The patients of diagnostic laparoscopy and cystectomy were discharged after 24 hours and TLH patients were kept for 72 hours. Patients were followed from the time of admission to the time of discharge and at one week.

\section{RESULTS}

A total of 217 laparoscopic procedures were carried out successfully during the study period. Majority $24.4 \%(n=53)$ patients were in age group 26-30 years. Diagnostic laparoscopy was done in 32 cases and operative laparoscopy in 185 cases. Major indication of diagnostic laparoscopy was infertility in 12 cases (Figure1). Lap cystectomy was the most common type of the surgery (Table 1). Dysfunctional uterine bleeding was the most common indication for TLH (Figure 2). Table 2 shows the complications of various laparoscopic procedures. Port site infection was noted in 10 cases, two of which required resuturing. The conversion to laparotomy was done in eight cases.

Table 1. Types of laparoscopic procedures $(n=217)$.

\begin{tabular}{|ll|}
\hline Types of procedures & N (\%) \\
\hline Diagnostic Laparoscopy & $32(15 \%)$ \\
Lap Oophorectomy & $10(5 \%)$ \\
Lap Cystectomy & $97(46 \%)$ \\
TLH & $33(16 \%)$ \\
LAVH & $7(3 \%)$ \\
Lap salpingectomy & $27(13 \%)$ \\
Bilateral tubal ligation & $3(2 \%)$ \\
\hline
\end{tabular}


hence immediate laparotomy was done and bleeding was taken into control. After one-pint whole blood transfusion postoperatively, patient was fine. Similar case has been reported by Hemal et al. ${ }^{7}$

Out of 217 laparoscopic procedures, 97 (46\%) cases were benign ovarian masses that underwent successful laparoscopic cystectomy (Table 1). Three cases required conversion to laparotomy due to severe adhesions and one due to vascular injury. The most common benign ovarian tumor was serous cystadenoma (54.6\%), dermoid (25.7\%), endometriosis (19.5\%). Ten (5\%) cases underwent oophorectomy.This contrasts with the study done by Shah et $\mathrm{al}^{4}$ where endometriosis was the commonest ovarian pathology followed by dermoid cyst. Endometriosis and dermoid cysts were the twocommon benign ovarian tumors in their series of Yuen et al. $^{8}$ Parker et al, ${ }^{9}$ similarly commented that planned laparoscopic approach was successful in $95.2 \%$ and the most commonly performed surgery was laparoscopic cystectomy in $75.3 \%$ of cases. Yuen et al, ${ }^{10}$ Parker et al, ${ }^{9}$ and Yuen et $\mathrm{al}^{8}$ concluded that operative laparoscopy should be the choice of treatment for benign adnexal masses.

Of all ectopic pregnancies during the study period, twenty-seven (13\%) cases underwent laparoscopic salpingectomy. Two cases underwent evacuation of hemoperitoneum for tubal abortion. Laparoscopic management was done in those cases which were hemodynamically stable and performed during only day time which was the main limitation in providing the laparoscopic service to ectopic pregnancy patients during emergency hours. Olagendoye et $\mathrm{al}^{11}$ found laparoscopic management feasible and safe in a study in $62 \%$ of patients while $31 \%$ of the patients required laparotomy following preliminary laparoscopy. Mohammed et $\mathrm{al}^{12}$ had compared laparoscopic and laparotomy management of ectopic pregnancy and concluded that laparoscopic surgeries for ectopic pregnancies are the most beneficial procedure with maximum safety and efficiency. Laparoscopic sterilization is not that common as government provides free program with an incentive.

Laparoscopic assisted vaginal hysterectomy (LAVH) was successfully completed in seven cases mainly for fibroid uterus during the initial years. Later Total Laparoscopic Hysterectomy (TLH) was preferred and was performed in $33(16 \%)$ cases, twelve for dysfunctional uterine bleeding (DUB), ten for fibroid uterus, five for adenomyosis and six for miscellaneous causes (Table 1, Figure 2). Four cases were converted into TAH because of adhesions. A study conducted in 1994 has shown that the risk of laparoscopic hysterectomy is same as that of abdominal and vaginal hysterectomy in skilled hands. ${ }^{13}$ This is similar to another study by Ribeiro et $\mathrm{al}^{14}$ which showed comparable safety of laparoscopic hysterectomy and abdominal hysterectomy. Average duration of hospital stay was 1.5 days in patients of diagnostic laparoscopic surgeries, 2 days in cystectomy cases and 3.5 days in hysterectomy cases. Studies by beginners also reported 2-6 days comparable hospital stay. ${ }^{15,16}$

\section{CONCLUSIONS}

The laparoscopic approach to gynecological surgeries at our hospital has demonstrated benefits of decreased morbidity, shorter hospital stay, and quicker return to normal activities. With the careful application of advanced laparoscopic techniques and sufficient surgical experience, laparoscopic surgeries can be implemented in a range of clinical scenarios and this report of our initial experience since the introduction of laparoscopic surgery in our department, has shown that laparoscopy is safe and useful in variety of gynaecological procedures.

\section{ACKNOWLEDGEMENTS}

We would like to express our sincere gratitude to all the patients included in the study and to Department of Obstetrics and Gynaecology, Department of Surgery and Department of Anesthesiology, Kathmandu Model Hospital for promoting and encouraging in the development of this new specialty.

\section{REFERNCES}

1. Vecchio R, Mac Fay den BV, Palazzo F. History of laparoscopic surgery. Pannminerrva Med. 2000;42(1): 87-90.

2. Padhye SM. Experience of laparoscopic sterilization under local anesthesia in camps in Nepal. J Inst Med. 1984;(6):31-6.

3. Nasir S, Hassan M, Tanau K, Abubakar PA, Ahmed Y, Umar AG. Experience with gynecological laparoscopy in a tertiary hospital, North-West Nigeria. Orient J Med. 2014;26:48-52.

4. Saha R, Shrestha NS, Thapa M, Shrestha J, Bajracharya J, Karki SC. Experiences of gynecological laparoscopic surgeries in a teaching hospital. J Nepal Health Res Counc. 2013;11(23);49-52.

5. Molloy D, Kaloo PD, Cooper M, Nguyen TV. Laparoscopic entry: a literature review and analysis of techniques and complications of primary port entry. Aust N Z J Obstet Gynaecol. 2002;42(3):246-54. 
6. Hasson MH. Open laparoscopy as a method of access in laparoscopic surgery. Gynecol Endosc. 1999;8(6):353- 62.

7. Hemal AK, Goel A. External Illiac Vein Injury and Its Repair During Laparoscopic Radical Cystectomy. JSLS : Journal of the Society of Laparoendoscopic Surgeons. 2004;8(1):81-83.

8. Yuen PM, Yu KM, Yip SK, Lau WC, Rogers MS, Chang A. A randomized prospective study of laparoscopy and laparotomy in the management of benign ovarian masses. Am J Obstet Gynecol. 1997;177(1):109-14.

9. Parker J, Bethune M, Lau P, Permezel M, Tan J, Byrne D. Operative laparoscopic management of adnexal cysts: initial experience at the Royal Women's Hospital 1991-1994. Aust N Z J Obstet Gynaecol. 1996;36(1):31-5.

10. Yuen PM, Rogers MS. Laparoscopic management of ovarian masses: the initial experience and learning curve. Aust N Z J ObstetGynaecol. 1994;34(2):191-4.

11. Olagendoye V, Adeghe J, Guirguis M, Dox C, Murphy D. Laparoscopic surgical management of ectopic pregnancy.
A district general hospital experience. Obstet Gynecol. 2000;20(6):620-3

12. Mohammed H, Maiti S, Philips G. Laparoscopic management of ectopic pregnancies of 5 years experience. Obstet Gynecol. $2002 ; 22: 411-4$

13. Liu C, Reich H. Complications of total laproscopic hysterectomy in 518 cases. Gynecol Endosc. 1994;3:203-8.

14. Ribeiro SC, Ribeiro RM, Santos NC, Pinotti JA. A randomized study of total abdominal, vaginal and laparoscopic hysterectomy. Int J Gynaecol Obstet. 2003;83(1):37-43.

15. Babu GS, Sujatha VV. Adoption of laparoscopy in a rural medical college hospital: minimal access surgery for masses a reality. J Womens Health Issues Care. 2013;2(4):1 4.

16. Badejko OO, Adeyemi AB, Kuti O, Ijarotimi O, Loto OM, Awowole IO. Operative gynecologic laparoscopy in IleIfe, Nigeria: Preliminary experience. J Gynecol Surg. 2013;29(4):186-9. 